\title{
FROM THE DESK OF EXECUTIVE EDITOR
}

(Birdem Med J 2015; 5(Supplement 1): 70)

The peer reviewed journal will be a valuable collection of different articles of all disciplines of medical and allied sciences. It publishes CME articles, article of researchers of different disciplines of BIRDEM and other institute of home and abroad. Any one can browse our web site (www.birdemmedj.org). You can search the journal in google and yahoo. Our ISSN is Print: 23053712. We got the registration from Bangladesh Medical and Dental council. We have been enrolled to BanglaJol. Any one can browse http://banglajol.info/bd/index.php/BIRDEM/index. We can get an item browsing the title here. The author now can submit the topic online.We have the system to estimate number of online of readers of our journal, the statistics is very much encouraging to us.

We are encouraged by our authors, we have good number of articles in hand which encouraged us to produce and publish this supplement copy. In this issue we have highlighted recent guidelines of hypertension management. We tried to incorporate diversified topics in our original, review article and case reports.

We are encouraged by our readers and their responses from home and abroad. We are very much thankful to our online readers, very much appreciate our authors who encourage us and enrich the journal with articles of variation.

Eagerly waiting for your valuable advice and new articles.

\section{Prof. Khwaja Nazim Uddin}

Executive editor

BIRDEM Medical Journal 